\title{
A IMPORTÂNCIA DA ANTROPOLOGIA CULTURAL PARA A PRÁTICA PEDAGÓGICA E FORMAÇÃO DA IDENTIDADE DA CRIANÇA: ESTUDO DE CASO EM UMA ESCOLA DE EDUCAÇÃO INFANTIL
}

\author{
TAVARAYAMA, Rodrigo ${ }^{1}$ \\ DUPIM, Priscila Nazaré Miranda ${ }^{1}$
}

\begin{abstract}
RESUMO: O presente trabalho teve como objetivo demonstrar que os conceitos elevados pela Antropologia Cultural, são benéficos para a Educação Infantil, favorecendo o convívio de pessoas diferentes no ambiente escolar, a valorização de todas as expressões culturais, e consequentemente agregando valores ao desenvolvimento da criança. Nota-se que no ambiente escolar a cultura elitista é predominante, ocasionando no preconceito cultural e social, desta forma a proposta apresentada leva a uma mudança desde a prática pedagógica até a convivência das crianças presentes no local. A metodologia utilizada para a elaboração deste, foi a revisão bibliográfica e a pesquisa de campo, com a técnica do questionário. A pesquisa foi realizada em uma escola de educação infantil, na cidade de Franca - SP, uma instituição particular, e também conveniada ao programa "Mais Creches" (onde a prefeitura em situações especiais, compra vagas da rede particular para atender a demanda de crianças), por fim os dados obtidos pela pesquisa foram analisado qualitativamente. Ao término deste estudo, podemos concluir que a Antropologia Cultural é um instrumento favorável à prática pedagógica, capaz de combater o preconceito no ambiente escolar, e valorizar a individualidade de cada aluno.
\end{abstract}

Palavras-chave: Palavras-chave: Antropologia Cultural. Educação Infantil. Diversidade Cultural. Preconceito na escola.

SUMMARY: The present work had as objective of demonstrating that the concepts raised by Cultural Anthropology are beneficial to Early Childhood Education, favoring the conviviality of different people in the school environment, the valorization of all cultural expressions, and consequently adding values to the development of the child. It is noticed that in the school environment the elitist culture is predominant, causing a cultural and social prejudice, in this way the proposal presented leads to a change from the pedagogical practice to the coexistence among the children present in the place. The methodology used for the elaboration of this, one was the bibliographical review and the field research, with the questionnaire technique. The research was carried out in a kindergarten, in the city of Franca - SP, a private institution that also agreed to the program "Mais Creches" (where the city hall, in special situations, buys form the private school systems the vacancy needed to meet the demand of children), finally the data obtained by the research were analyzed qualitatively. At the conclusion of this study, we could conclude that Cultural Anthropology is an instrument favorable to pedagogical practice, capable of combating prejudice in the school environment, and valuing the individuality of each student.

Keywords: Cultural Anthropology. Child education. Cultural diversity. Prejudice in school.

\section{INTRODUÇÃO}

Para a formação da identidade da criança, é necessário que ela conviva com outros diferentes dela, e é na escola que ela tem essa experiência, do conviver com pessoas de culturas, valores, regras, diferentes da sua. Para que essa relação seja favorável ao desenvolvimento do aluno, o educador deve mediar essas relações, trabalhando a valorização das diferenças culturais ali apresentes.

A antropologia cultural nos ensina a olhar o outro sem pré-julgamentos, a fim de entender, compreender o diferente, praticando assim a alteridade, que segundo Aquino ( 1998 ), é o reconhecimento do outro, na sua diferença. Neste contexto, é possível afirmar que a antropologia

\footnotetext{
${ }^{1}$ Fundação Educacional de Ituverava
} 
cultural, aplicada a educação infantil, pode vir a contribuir consideravelmente para o desenvolvimento da criança.

O ambiente escolar é um espaço importante para a formação da criança, é onde ela vai interagir com pessoas de costumes diferentes aos dela, o que é saudável ao seu desenvolvimento, uma vez que ela terá contato com a diversidade cultural, aprendendo a conviver em sociedade e com o diferente. Partindo do pressuposto de que este espaço é benéfico para ela, porque na prática ainda encontramos tanto preconceito em nossas escolas? Porque a cultura elitista ainda prevalece neste ambiente? Porque há tanta distinção e discriminação de pessoas?

O objetivo deste estudo foi de conscientizar o professor/leitor sobre os benefícios da antropologia cultural para a educação infantil, a fim de que este o aplique a sala de aula, a sua escola, podendo ser um suporte para a prática pedagógica daquele que vir a conhecê-lo.

Esse trabalho foi elaborado com base em revisões bibliográficas, através da leitura de livros, revistas e artigos científicos acerca do tema, para tanto utilizamos Áries (1975), Cohn (2005), Gusmão (2000), Perrenoud (2001), Ullman (1983), bem como outros autores que nos levaram ao desenvolvimento da fundamentação teórica deste estudo. Após este levantamento, e elaboração desta reflexão, foi realizada uma pesquisa de campo, com professores de uma escola de educação infantil, na cidade de Franca, interior de São Paulo, com objetivo de conflitar os dados colhidos, por meio de questionários, com o material teórico, analisando-os qualitativamente.

O estudo realizado nos permitiu compreender que há uma discriminação cultural em nossas escolas, e que este é um problema emergencial da educação, sendo assim necessário uma mudança de postura, por parte dos professores, e consequentemente dos alunos; a prática da antropologia cultural no ambiente escolar é um instrumento favorável para que essa mudança aconteça de fato.

\section{BREVE CONTEXTO HISTÓRICO ACERCA DA ANTROPOLOGIA CULTURAL}

\subsection{O surgimento da Antropologia}

A Antropologia é uma ciência que tem como objetivo estudar o homem de forma mais aprofundada, uma reflexão sobre a diversidade cultural humana. Por meio dela podemos compreender as questões biológicas que envolvem o ser humano, assim como conhecer desde as primeiras formas de organização da sociedade, até a maneira como a cultura é transmitida de geração em geração.

De acordo com Marconi e Presotto (2010, p. 1) "etimologicamente, o termo antropologia (anthropos, homem; logos, estudo) significa o estudo do homem. Como ciência da humanidade, ela se preocupa em conhecer cientificamente o ser humano em sua totalidade". Podemos dizer ainda que ela, de certa forma, é a chave para a compreensão do homem.

Como ciência de fato, a Antropologia surgiu no contexto do Iluminismo, onde o interesse anterior pelo mundo, sua origem, o Criacionismo ("Deus" como o criador do mundo e das coisas), deixou de ser a maior especulação dos pensadores, dando espaço as curiosidades acerca do homem, o surgimento da espécie humana, sua evolução, e também sua forma de se organizar socialmente e culturalmente. Ou seja, quando o Teocentrismo (Deus no centro de todas as questões), deu espaço ao Antropocentrismo (homem no centro das ideias).

\subsection{A Antropologia Cultural e seu objeto de estudo}

A Antropologia Cultural tem como principal interesse o homem e suas relações culturais, como a 
cultura é transmitida, qual valor ela tem para o homem, como deve ser e, como é, analisada pelas outras culturas.

Nenhum de nós nascemos isolados, em uma sociedade sem costumes, pelo contrário, ao nascermos somos inseridos em grupos, o qual recebemos como forma de "herança" de nossos pais ou grupos aos quais pertencemos.

Segundo Tomazi (1997), todos os povos, grupos, pessoas, geram uma cultura, que está diretamente relacionada ao seu tempo e espaço; assim toda forma de agir, sentir e pensar do indivíduo se origina de uma prática coletiva.

Cultura é portanto isso, costumes passados de geração em geração, que na maioria das vezes não são questionados, mas simplesmente apreendidos pelo indivíduo que os recebem. Obviamente, essa não é uma regra geral, há aqueles que não se identificam com a cultura que receberam, e vivem de outra forma, ou até mesmo a transforma, ainda assim este procura um outro grupo ao qual se identifique, para compartilhar as mesmas experiências, costumes, valores.

A Antropologia Cultural, enquanto ciência, se interessa pelas manifestações culturais de diferentes povos, mas não para "enquadrá-los" aos padrões sociais, tão menos para qualificar, ou valorizar uma cultura e menosprezar outra, pelo contrário, essas manifestações são estudadas a fim de conhecer o outro, seus valores, manifestações religiosas, políticas, sob o olhar da alteridade (que é se colocar no lugar do outro, ver com os olhos do outro, por meio das experiências do outro, sua vivencia, e não com os seus conceitos morais e éticos).

De acordo com Ullmann (1983, p. 42):

[...] A Antropologia mostra que a humanidade é única, singular. Apresenta os valores de todos os povos e culturas. Ensina a aborrecer o fanatismo etnocêntrico, insensato, quer ele proclame a superioridade racial, quer alardeie a sua cultura como única válida. A Antropologia Cultural inculca a igualdade dos povos, com suas aspirações de mais variada natureza. E traz a consciência de todos o fato de que, conquanto cidadãos do mundo, não é possível sopitar a ânsia pelo transcendente, manifesto em todas as culturas.

Conviver com outras culturas, aprender com o outro, ver seus costumes, seus pensamentos, sua história, muda a forma como nos relacionarmos com ele. Ao conhecermos o que impulsiona o outro a agir de tal modo, a crer em tal manifestação religiosa, a comer tal tipo de comida, a se vestir com tais vestimentas, podemos compreender o seu ponto de vista, assim como valorizar essa cultura. Assim como nos propõe Morais (1992), não é possível viver em uma sociedade e ignorar sua cultura, pois essa influência nossa permanência e atuação no mundo.

É por meio da educação que podemos ensinar as pessoas a prática da alteridade ${ }^{2}$ e a postura relativista $^{3}$, assim como, a reagir de maneira natural as diferenças encontradas em nosso meio, sejam elas econômicas, raciais, de gênero, ou qualquer outra forma de diferença encontrada em nossas convivências sociais. É importante ainda destacar que relativizar não significa somente se colocar no lugar do outro, as compreendê-lo na sua diferença. Partindo deste princípio de que os seres humanos são produtores de cultura e que não há indivíduo sem a mesma, podemos delinear como a antropologia cultural e seu cabedal teórico pode vir a contribuir para a educação. Nas palavras de Tomazi (1997, p. 139):

\footnotetext{
${ }^{2}$ A antropologia é também conhecida por excelência como a ciência da alteridade, uma vez que seu objetivo é compreender o homem e sua cultura. Pode-se dizer que a alteridade é a capacidade de se colocar no lugar do outro a fim de compreendê-lo em sua plenitude.

${ }^{3}$ A postura relativista pressupõe que uma cultura deve ser compreendida e analisada dentro de seu próprio contexto, livre de qualquer julgamento de valor pré-concebido, ou seja, não se pode julgar o "diferente" a partir de uma visão dominante, uma vez que é preciso compreender melhor o outro, o que incide muitas vezes em contrariar interesses da cultura dominante.
} 
É no interior desse quadro que surge a educação: um processo em que essa cultura é transmitida aos membros mais jovens desse grupo ou dessa sociedade, como forma inclusive de perpetua-la. Naturalmente esse processo não se dá de maneira exclusiva na escola, mas ela é um espaço privilegiado para isso, já que é uma instituição culturalmente construída para que certo repertorio cultural seja transmitido. Portanto, entre cultura e educação há uma relação muito intima. Afinal, transmitimos conhecimentos, crenças, hábitos, valores, enfim, modos de vida. É um patrimônio intelectual e espiritual, uma herança coletiva, fruto de ação coletiva que se preservou de alguma forma. O que é isso senão cultura?

É evidente que educação e cultura caminham juntas, sendo assim, pode-se dizer que a antropologia cultural é indispensável para a formação de um indivíduo mais consciente de seus valores, de seus direitos como cidadão, e de seu dever de trabalhar a favor de um mundo melhor para todos, independentemente das crenças, cor, etnia, nível econômico, ou qual outra característica que possa ser vista como diferente.

\section{A INFÂNCIA E A EDUCAÇÃO INFANTIL}

\subsection{Breve conceito de infância}

Antes de discorrer sobre a história da Educação Infantil, é necessário conhecer e conceituar brevemente o que vem a ser a infância ${ }^{4}$. Pode-se dizer que a infância é entendida sob diferentes perspectivas e varia de cultura para cultura. De acordo com Fernandes e Kuhlmann Júnior (2004), a palavra infância nos remete ao período da vida de construção/apropriação da vida humana, ou seja, período de descobrimentos.

Quando falamos em infância, logo nos vem à mente um período da vida da pessoa que requer muitos cuidados, contudo, essa é uma preocupação moderna, até algum tempo atrás, a criança era compreendida como uma miniatura do adulto, se vestia como um adulto, participava das mesmas festas e locais; ela era cuidada pela família por um curto período de tempo, enquanto ainda era engraçadinha e bonitinha, tratada como um animalzinho de estimação, e logo que passava os primeiros anos, ela era retirada do convívio familiar, a educação só acontecia pela aprendizagem, onde convivendo com outros adultos, aprendiam a fazer o que eles faziam (ARIES, 1981).

Essa desvalorização da criança segue até os séculos XV, XVI, XVII, mas a partir deste período acompanhando as mudanças da sociedade, a criança passa a ser vista como um ser com particularidades, diferente dos adultos, um ser com capacidades (KULLER, 2009).

O pensador Jean-Jacques Rousseau foi um grande influenciador desse momento, destacando que a criança precisa ser cuidada desde o nascimento, até os anos que seguem sua infância, pois essa não é um adulto em miniatura, mas um ser com características próprias (NETO, 2001).

Nesta perspectiva, Rousseau rompe com a ideia de que a criança deve aprender observando o adulto, tentando ser como ele; para o autor, é preciso, de forma intencionada, educar a criança, prepará-la para a sociedade, mencionando a importância dos pais (em especial da mãe), assim como dos professores em promover a educação de maneira adequada as crianças.

Rousseau (2004), destaca que toda criança deve ser preparada para a vocação comum, que é a condição de homem, independente daquilo que a criança virá a ser, ela deve antes de tudo ser preparada para a vida humana.

A partir deste momento, chegamos ao conceito de infância moderno, onde a criança aprende com

\footnotetext{
${ }^{4} \mathrm{O}$ intuito desta seção não foi discorrer criteriosamente a respeito do conceito de infância, mas de situar o leitor para que possa compreender como o conceito de infância sofreu mudanças ao longo do tempo.
}

Nucleus,v.16,n.2,out.2019 
a sociedade que está inserida e ao mesmo tempo atua nela, fazendo parte dos diversos grupos sociais presentes nesta, e enfrentando as mesmas situações que estes enfrentam. Segundo Fernandes e Kuhlmann Jr. (2004, p. 30):

Um guarda-chuva a abrigar um conjunto de distribuições sociais, relacionadas às diferentes condições: as classes sociais, os grupos etários, os grupos culturais, a raça o gênero; bem como as diferentes situações: a deficiência, o abandono, a vida no lar, na escola (a criança e o aluno) e na rua (como espaço de sobrevivência e/ou de convivência/brincadeira). É nessa distribuição que as concepções de infância se amoldam às condições especificas que resultam na inclusão e na exclusão de sentimentos, valores e direitos.

Enfim, a concepção de infância sofreu grandes transformações ao longo da história, acompanhado o desenvolvimento social. A concepção de criança mudou com o passar do tempo, assim como o que ela podia ou não fazer, e até se manifestar.

\subsection{O desenvolvimento da Educação Infantil no Brasil}

$\mathrm{O}$ primeiro ato legal que garantiu o direito a educação desde o nascimento à criança, foi na Constituição Federal de 1988. Oficialmente, até o momento, não existia obrigatoriedade, o que havia era instituições de caridade, grupos religiosos, que assumiam o trabalho de cuidar da alimentação, saúde, das crianças, filhos dos cidadãos de baixa renda, que não tinham condições de pagar uma babá para cuidar dos seus, assim como faziam os filhos dos homens de classe alta (KUHLMANN, 2004).

De acordo com a Constituição Federal de 1988 (BRASIL, 1988a, s/p):

Art. $7^{\circ}$ - São direitos dos trabalhadores urbanos e rurais, além de outros que visem à melhoria de sua condição social.

XXV-assistência gratuita aos filhos e dependentes desde o nascimento até seis anos de idade em creches e pré-escolas.

A partir desse momento a Constituição Federal passa à assegurar o direito a educação para as crianças pequenas, porém, somente para os filhos dos trabalhadores, aqueles em que pai e mãe, estivessem exercendo algum tipo de trabalho legal.

Passados dois anos da Constituição de 1988, é aprovado em 1990 o Estatuto da Criança e Adolescente (BRASIL, 1990), que visa resguardar os direitos das crianças e adolescentes, elevando-os a categoria de cidadãos. E em 20 de dezembro de 1996, é criado a Lei de Diretrizes e Bases para a Educação, a LDB, que pode ser considerada de grande importância para a consolidação da Educação Infantil no Brasil.

Segundo a Lei de Diretrizes e Bases da Educação Nacional (BRASIL, 1996, s/p):

Art. 54. É dever do Estado assegurar à criança e ao adolescente:

I - ensino fundamental, obrigatório e gratuito, inclusive para os que a ele não tiveram acesso na idade própria;

II - progressiva extensão da obrigatoriedade e gratuidade ao ensino médio;

III - atendimento educacional especializado aos portadores de deficiência, preferencialmente na rede regular de ensino;

$\mathrm{V}$ - atendimento em creche e pré-escola às crianças de zero a cinco anos de idade;

Observa-se que pela primeira vez na história a Educação Infantil é colocada como primeira fase dos 
níveis escolares. De acordo com o Art. 21 da LDB (BRASIL, 1996), a educação básica passou a ser formada pela educação infantil, ensino fundamental e ensino médio.

Em 1998 o Ministério da Educação e do Desporto (MEC) lança o Referencial Curricular para a Educação Infantil (BRASIL, 1998b), garantindo que nessa etapa de aprendizagem além do cuidar, fosse também exercidas atividades bem planejadas, a fim de auxiliar no desenvolvimento físico, psíquico e motor da criança.

O Ministério da Educação (MEC) declara o ano de 2006 como sendo o Ano da Política Nacional da Educação Infantil, estabelecendo ações norteadoras que são praticadas ainda hoje nas escolas, dentre tantas observações importantes destaca-se a necessidade do grupo escolar, que se caracteriza pela gestão escolar, professores, funcionários, alunos, pais e comunidade, trabalharem em conjunto, na busca de uma educação de qualidade, que transforme a vida da comunidade local, valorizando sua cultura, seus ideais.

Assim, observando o desenvolvimento da Educação Infantil no Brasil, podemos destacar que ela acompanhou o processo de modificação da sociedade e graças a isso a criança vêm conquistando seu lugar na sociedade, sendo hoje vista como um cidadão de direitos, que atua na sociedade e a transforma.

\section{ANTROPOLOGIA CULTURAL E EDUCAÇÃO INFANTIL}

\subsection{Conviver com a diversidade: aspecto necessário para a formação da identidade da criança}

Quando nasce uma criança, ela está inserida em um meio cultural e aprende com os seus os costumes vivenciados por eles, portanto a formação da identidade do ser humano acontece no convívio, na interação com o outro, nas observações feitas sobre o que o seu próximo pensa, como age, nas informações que ele transmite.

Piaget (1994) abordou o desenvolvimento moral da criança, ressaltando que essa se desenvolve moralmente, de acordo com sua convivência grupal. As normas e regras vivenciadas em seu meio, são absolutas para ela, em especial as impostas por seus pais, ou por aqueles a quem prestam respeito.

Nesse contexto, onde a criança observa e se molda de acordo com a sociedade em que está inserida, podemos transportá-lo para a sala de aula. Lá a criança aprenderá aquilo que o seu professor manifesta, pois ele é um dos seres respeitados por ela, como se fosse um espelho.

A convivência com outro leva o indivíduo a questionar-se sobre sua própria personalidade, seus atos, e a partir desse questionamento modificar aquilo que considera necessário. Com a criança não é diferente, uma vez que é na socialização que ela constrói sua identidade. De acordo com Gusmão (2000, p. 14) "a questão da identidade do eu, portanto, passa pelo mundo onde estou, pertenço e vivo, mas só é objeto de meu pensar enquanto uma questão, um problema, quando me defronto com o outro diferente de mim e aí me pergunto: quem sou?".

Para que a formação da identidade da criança seja beneficiada pelo convívio com o diferente, a alteridade deve ser o instrumento fundamental na prática cotidiana. Gusmão (2012), ao falar sobre a alteridade, entende ser essa a consciência de que o outro está presente em seu mundo, tanto quanto ele está presente no mundo do outro, e é essa afirmativa que nos desafia, afinal somos todos diferentes culturalmente, e em nosso contexto atual, as relações interpessoais são marcadas pela questão da hierarquia de poder. Portanto, como conviver com esse outro, diferente à nós, sem confrontos, sem conflitos, sem tentar fazer dele um sujeito igual a mim, negando suas convicções? Como conviver com as diferenças e ainda assim estabelecer relações sadias, solidarias? Por fim, ela conclui afirmando ser esse um dos grandes desafios da escola e da educação.

Desta forma, entendemos que é na escola que a formação para a convivência com as diferenças de 
fato se inicia, pois é no ambiente escolar que a criança tem seu primeiro contato com outra forma de realidade e organização da sociedade. Gusmão (2000) nos leva a alguns questionamentos, tais como: como as instituições escolares têm trabalhado a questão das diferenças? O cotidiano escolar tem proporcionado a relação de troca de experiências, e de respeito mútuo entre as crianças, que levam a formação da personalidade?

Repensando a prática pedagógica na sala de aula, nos deparamos com a triste realidade de que, inúmeras vezes, a escola tem afirmado que todos são tratados da mesma maneira, que não há diferenças, diminuindo assim o outro para se fazer igual ao todo, ou seja, usa o discurso da homogeneização para apagar as diferenças e diversidade cultural da sala de aula. Se as diferenças de fato existem, esse comportamento não está correto, as diferenças existentes entre os alunos e devem ser compreendidas, aceitas e respeitadas.

Segundo Gusmão (2000), é comum na escola ouvir que "todos são iguais", mas na realidade sabemos que essa igualdade não é real, cada aluno tem sua própria história; essa atitude nega as diferenças existentes no ambiente, "colocando todos os alunos no mesmo saco".

Portanto, na sala de aula, a alteridade é uma questão inevitável, ela deve ser trabalhada dentro do currículo escolar, uma vez que ela está inserida no currículo oculto ${ }^{5}$, que para Silva (1995), é a consequência do que é ensinado de forma não intencional na escola, através de elementos presentes no ambiente escolar; pois as ações observadas pelas crianças são apreendidas facilmente. Quando a prática pedagógica não trabalha essas diferenças, com naturalidade, não excluindo e nem diminuindo nenhuma cultura, esses problemas originados pela constatação do singular, desencadeiam uma série de consequências, pode-se dizer que a falta da alteridade dentro de um ambiente gera mais conflitos, assim como preconceito escolar, do qual falaremos à seguir.

\subsection{O preconceito na escola}

Ao chegar à escola o aluno traz consigo os costumes herdados por sua comunidade, sua família, alguns tem costumes considerados pelo senso comum "normais", e outros tem costumes "diferentes". Aqueles que fazem parte da cultura tradicional da escola se sentem familiarizados ao chegarem lá, já os que tem outros costumes, não conseguem se adaptar.

Para Perrenoud (2001, p. 53):

Tanto hoje como ontem, uma parte dos alunos encontra na escola uma cultura com a qual está familiarizada, enquanto outros se sentem exilados. Isso acontece com alunos imigrantes ou provenientes de famílias que se estabeleceram há pouco em outro país. Mas também ocorre, de modo menos visível, com os filhos das classes populares.

Essa afirmativa, citada no trecho acima, nos leva a conclusão de que infelizmente, ainda nos dias de hoje, a prática pedagógica valoriza uma cultura elitista, excluindo aqueles que fazem parte das classes populares.

Sabemos que todo aluno tem sua formação particular, uma cultura originada de seu grupo, sua comunidade, seu bairro, sua família, assim como de sua classe social. Na escola, o aluno que segue as práticas impostas pela cultura elitista, é considerado um "bom aluno", enquanto aqueles que praticam outras maneiras, são inúmeras vezes taxados como "não rentáveis". Quando o aluno procede de uma família que valoriza os estudos, que tem o hábito da leitura presente entre os seus, ao chegar à escola, a

\footnotetext{
${ }^{5} \mathrm{O}$ currículo oculto diz respeito a todos os aspectos que compõe o ambiente escolar, mas que não fazem parte do currículo oficial prescrito ou real, mas que contribuem para que a aprendizagem ocorra, em outras palavras, não consta no planejamento do professor, como por exemplo possibilitar aprendizagens importantes para a vida.
} 
prática faz referência a sua vivência cotidiana, fazendo com que se sinta "em casa". Por outro lado, aqueles que cresceram entre os terrenos baldios, estádios de futebol, ou até mesmo como única fonte de informação a televisão, ao adentrar a escola não verá nenhuma relação com a sua realidade (PERRENOUD, 2001).

Essa cultura elitista, valorizada pela sociedade, não escapa aos muros da escola, à medida que grande parte dos professores fazem parte dessa cultura, e assim como os seus, pensam e agem da mesma forma, aceitando somente aquilo que vêm como o correto. Encontramos ai uma grande distância entre a realidade do professor com a do aluno, e de certo modo aquele que deveria promover a igualdade, e ensinar sobre a alteridade, é o primeiro a propagar o preconceito em sala de aula.

\subsection{Antropologia Cultural na educação Infantil: por uma prática libertadora}

Como vimos anteriormente, para a formação integral do sujeito, é necessário sua convivência com o diferente, na escola é tarefa do educador trabalhar a valorização de toda cultura presente, para isso precisamos conhecer nosso aluno, conhecer sua realidade, sua comunidade local, sua família, seus problemas, gostos e valores.

De acordo com Cohn (2005), devemos dispor nossas imagens preconcebidas, e olhar para o aluno entendendo a realidade que ele tem a nos oferecer, a partir do seu próprio ponto de vista.

Nessa perspectiva, podemos dizer que a antropologia da criança busca por em prática uma pedagogia que tenha como propósito conhecer de fato o aluno, que trabalhe a alteridade, na intensão de proporcionar um processo ensino-aprendizagem que valorize as individualidades e diversidade presente dentro do ambiente escolar e seu entorno.

Segundo Cohn (2005) a antropologia é um instrumento para conhecer o aluno, tendo inclusive uma metodologia própria para isso, chamado de etnografia. Diversos estudiosos de crianças, tem utilizado esse método antropológico, na busca de conhecer melhor a criança, e seu habitat. Para colocar esse método em prática, o pesquisador deve conviver, de maneira direta, na vida e no mundo do aluno, ou seja, é uma observação da realidade, dos afazeres, do investigado; esse propõe que mais que observar, cabe ao pesquisador, se colocar no lugar do outro, excluindo os seus pré-conceitos, afim de compreender os motivos que o outro tem para pensar e agir de tal modo. Pode-se dizer que o educador deve aprender a fazer da sala de aula seu campo de pesquisa e se permitir a enveredar-se no mundo do outro.

O método da etnografia pode ser aplicado a sala de aula, o professor deve ser um pesquisador, que vai em busca da realidade de seu aluno, e observando as particularidades da criança, é preciso que na escola elas sejam respeitadas.

Conhecer o aluno, e suas particularidades, leva o professor a compreender os seus motivos, suas práticas, e consequentemente, o seu modo de aprender aquilo que lhe é ensinado. Isso faz com que o educador tenha uma nova postura frente as diferenças, respeitando o tempo de aprendizagem de cada um, entendendo que o processo ensino-aprendizagem não pode ser uniforme, pois cada aluno tem seus seus próprio ritmo, suas dificuldades e facilidades na aprendizagem (COHN, 2005).

$\mathrm{Na}$ Educação Infantil, período em que a prática pedagógica está associada à educação da criança, e também as questões do cuidar, o educador tem o papel de ensinar as crianças pequenas a respeitar as diferenças, a conviver com o outro e valorizar o pensamento de cada um, ainda que seja diferente a sua própria maneira de ver as coisas. É na troca de experiências, na convivência diária, é que a práticas impostas pela cultura elitista, é considerado um "bom aluno", enquanto aqueles que praticam práticas impostas pela cultura elitista, é considerado um "bom aluno", enquanto aqueles que praticam ara Felipe, Albuquerque e Corso (2016) a criança pequena irá agir de acordo com o que o ambiente em que 
está inserida lhe propor, é na troca de experiências, nas respostas adquiridas desse meio, e das pessoas que o compõem, que ela vai se moldando e dando significado as coisas.

Desta forma a prática pedagógica, na sala de aula da educação infantil, deve ser também orientada dentro dos princípios da antropologia cultural, valorizando a cultura de todos os indivíduos e a troca de experiências, assim como o respeito entre as diferenças, a fim de proporcionar um ambiente solidário e acolhedor, onde os diferentes não sejam os "errados", os esquisitos e/ou aberrações. É no ambiente escolar que o aluno deve encontrar o suporte necessário para desenvolver-se e atuar na sociedade, livre de preconceitos e dos estereótipos impostos por ela.

\section{ANÁLISE E DISCUSSÃO DOS DADOS}

Afim de conflitar o material teórico elaborado, foi aplicado um questionário a quatro professores de uma escola de educação infantil, localizada na cidade de Franca, interior do Estado de São Paulo. Por ser uma escola pequena que conta com aproximadamente 80 crianças, o número de professores na pesquisa foi também pequeno, entretanto uma vantagem na escolha da instituição é que a escola é particular, mas atende também crianças do "Mais Creches", programa municipal, onde para atender a demanda de crianças a prefeitura "compra" vagas na rede particular, o que representa uma grande diversidade socioeconômica e cultural na escola.

Primeiramente procuramos conhecer melhor os professores, traçando um breve perfil dos mesmos. A tabela 1 abaixo classifica os professores, quanto ao sexo, idade, formação, pós-graduação, tempo de magistério e séries que trabalham.

Tabela 1. Perfil e dados dos entrevistados

\begin{tabular}{c|c|c|c|c|c|c}
\hline Entrevistados & Sexo & Idade & $\begin{array}{c}\text { Formação } \\
\text { (Graduação) }\end{array}$ & Pós-Graduação & $\begin{array}{c}\text { Tempo de } \\
\text { atuação na ed. } \\
\text { Infantil }\end{array}$ & $\begin{array}{c}\text { Fase que atua } \\
\text { no momento }\end{array}$ \\
\hline P1 & F & 29 & Pedagogia & $\begin{array}{c}\text { Psicopedagogia } \\
\text { Especialização em } \\
\text { Ed. Especial }\end{array}$ & 5 Anos & Maternal I e II \\
\hline P2 & F & 25 & Pedagogia & Não possui & 1 Ano & $\begin{array}{c}\text { Maternal II e } \\
\text { Fase I }\end{array}$ \\
\hline P3 & F & 32 & Pedagogia & Não possui & 9 Anos & Fase II \\
\hline P4 & F & 22 & Pedagogia & Não possui & 1 Ano & Maternal I \\
\hline \multicolumn{7}{|c|}{ Fonte: Dados da autora (2018). }
\end{tabular}

A segunda questão teve como objetivo conhecer as diversidades existentes entre os alunos, assim como a percepção das professoras quanto as diferenças. Foi perguntado se na sala de aula em que atuam havia muitas diferenças entre os alunos e quais seriam as mais evidentes.

É possível observar pelas respostas das professoras, que sim, elas são conscientes das diferenças presentes na sala de aula, e unanimemente apontaram a estrutura familiar como a maior diferença entre os alunos. Perrenoud (2001, p.49), afirma que por experiência própria todo professor sabe que as crianças são diferentes, seja pelo ritmo de aprendizagem, pela cultura, ou pelo apoio familiar que recebem, porém a questão é como tem sido trabalhado essas diferenças na sala de aula, para ajudar os menos favorecidos.

A próxima questão levada as participantes segue este mesmo pensamento do autor, é evidente que os professores reconhecem que há diferenças no ambiente escolar, assim foi perguntado como elas trabalhavam essas diferenças em sala de aula. 
As professoras afirmaram trabalhar as diferenças por meio do lúdico, priorizando a igualdade de direitos a todos os alunos. Essa realidade citada por elas, por mais que seja agradável e desperte o interesse da criança não é suficiente para que o aluno saiba lidar com as diferenças presentes no ambiente. Podemos observar que é necessário oportunizar momento específicos para aprender sobre diversidade, é preciso que desde o planejamento do projeto político pedagógico todas as atividades da escola estejam voltadas para a valorização do outro.

A escola deve ser um ambiente que priorize a convivência e as relações pessoais entre os alunos, a troca de experiências, com o objetivo de levar a criança à compreensão daquilo que o outro é; conhecer o outro, sua realidade, levar ao entendimento de sua cultura, sua forma de ser, e ainda possibilitar que eu descubra aquilo que realmente sou. Araújo (1998, p.45), entende que "necessitamos pensar em uma escola mais democrática, baseada em relações que respeitem a diversidade e a pluralidade de pensamento, de sentimento, de conduta [...] uma escola que propicie um ambiente cooperativo".

Outro aspecto a ser considerado é que na prática pedagógica os professores oferecem aos alunos uma única expressão cultural, a linguagem trabalhada, os autores de que se fazem referência, as músicas utilizadas, e todas as outras manifestações culturais das atividades propostas, seguem o padrão social; esta atitude precisa ser mudada, o pluralismo cultural deve ser adotado na sala de aula. Cortesão e Stoer (1999, p. 56) relatam sobre o daltonismo cultural presente nas escolas, propondo que a prática pedagógica seja a maneira de romper essa realidade, a fim de levar trabalhar o multiculturalismo ${ }^{6}$ dentro da sala de aula.

A quarta questão apresentada por meio do questionário teve como objetivo analisar o que o professor pensa a respeito das diferenças na sala de aula, assim como se a presença delas pode atrapalhar ou ajudar no processo de ensino-aprendizagem. Encontramos afirmativas como:

Ajuda, em especial no convívio social e comportamental. Exemplo: o que sabe mais ajuda o que sabe menos, e a criança que apresentava mal comportamento mudou completamente pela boa influência da amiga com bom comportamento (P3)

Não atrapalha, o berçário é composto por alunos de diferentes interesses e atitudes, isso auxilia no desenvolvimento de cada criança (P4).

Das respostas obtidas, foi possível observar que somente a professora 4 destacou a importância de conviver com a diversidade para o desenvolvimento da criança, as outras três também disseram que conviver com o diferente é importante, porém com o objetivo de influenciar aquele tido como "mal aluno", a fim de que se enquadre ao comportamento do "bom aluno".

Encontramos nessas afirmações um grande problema social reproduzido na escola, temos como comportamento adequado aquele que se assemelha ao nosso, enquanto os outros devem ser trabalhados para chegar a este patamar. O educador Paulo Freire ao traçar rumos para uma educação libertadora, tinha esse problema como grande preocupação.

De acordo com Freire (1983, p. 96):

Como aprender a discutir e debater com uma educação que impõe? Ditamos ideias. Não trocamos ideias. Discursamos aulas. Não debatemos ou discutimos temas. Trabalhamos sobre o educando. Não trabalhamos com ele. Impomos-lhe uma ordem a que ele não adere, mas se acomoda.

Dentre as afirmativas analisadas foi possível destacar dois aspectos discutidos em nosso trabalho de revisão bibliográfica, o primeiro onde a escola já aponta como principal diferença entre os alunos a

\footnotetext{
${ }^{6} \mathrm{O}$ multiculturalismo pode ser entendido como sendo a convivência pacífica de culturas diferentes em um mesmo ambiente, trata-se de um conceito importante para a educação, uma vez que as reflexões dentro de sala de aula devem trabalhar a questão das diferenças, promovendo uma conscientização e aprendizagem de respeito as diferenças culturais que existem na sociedade.
}

Nucleus,v.16,n.2,out.2019 
estrutura familiar, dando indícios de que acreditam ser a família a maior responsável pela forma de ser e agir das crianças; o segundo mostra a realidade elitista da escola, que considera "mal aluno" aquele que não se enquadra aos comportamentos esperados pelas professoras.

Com base nisso, a próxima questão analisada foi a forma como as escolas trabalham as dificuldades de aprendizagem dos alunos, pois sabemos que frequentemente o fracasso escolar é atribuído a família. Assim, foi perguntado se era comum na sala de aula ter algum aluno com maior dificuldade em aprender do que os outros e se isso é uma realidade da sala de aula e qual seria o motivo aparente para tal dificuldade. Destacamos duas falas das entrevistadas a respeito do tema:

Sim. As causas estão relacionadas à estrutura individual e familiar das crianças. Organização familiar: pais ausentes, a criança aparenta ser desassistida pela família, contexto familiar violento. Fator individual: falta de interesse, incentivo e estimulo do meio em que está criança está inserida (P1). Sim, alunos com grau/nível de dificuldades diferentes. Acontece na sala de aula. Os motivos que percebo são os estímulos que as crianças rebem ou não recebem de seus familiares. A atenção e a concentração a ser desenvolvida na criança; o reconhecer as dificuldades que o aluno/filho tenha e priorizar os estímulos desde "bem cedo" (P2).

As professoras foram unânimes em apontar que as dificuldades eram responsabilidade da família, que não apoiava, não estimulava as crianças, isentando-se da responsabilidade dessa. Apenas uma professora, a P2, demostrou por um instante que o professor também tem falhado ao trabalhar as dificuldades de aprendizagem.

Conhecer as diferenças e realidades dos alunos, suas particularidades, é aspecto fundamental para que o processo de ensino-aprendizagem seja eficaz, atribuir toda responsabilidade do fracasso da aprendizagem a família é cômodo ao professor, mas não a solução para o problema. Perrenoud (2001, p. 49) nos apresenta uma estratégia para trabalhar essas diferenças, segundo ele com o mesmo ensino não é possível atingir a todos, é preciso ter um trabalho diferente, dedicar mais tempo e mais recursos para ajudar os menos favorecidos.

Essa prática em que a escola se ausenta das dificuldades do aluno transferindo-a para o seu meio social e familiar é comum, e uma das questões que leva ao preconceito cultural na escola. Entretanto, falar sobre o preconceito existente no ambiente escolar é um tabu para os professores, pois conscientes ou não acabam mascarando essa realidade. A sexta questão da pesquisa procurou analisar se o preconceito é uma questão social que reflete na escola e se os educadores notavam se alguma criança sofria com esse problema em sua sala de aula.

Todas as professoras disseram não enfrentar o preconceito na sala de aula. No entanto, é preciso destacar que mesmo elas tendo afirmado que não possuem este problema, isso não significa que ele não deve ser trabalhado e/ou combatido dentro do ambiente escolar. Outro ponto que vale a pena destacar é que a escola é um ambiente de choque de culturas, sendo assim podemos dizer que nã há escola sem conflitos e/ou problemas, ao afirmar que não há nenhum tipo de preconceito nota-se que muitas vezes eles podem ter sido apagados, negados ou negligenciados pelas próprias educadoras.

De acordo com Itani (1998), o preconceito faz parte de nosso cotidiano e a sala de aula não escapa disso. Para poder trabalhar essa questão é preciso compreendê-la, encontrar sua manifestação

Portanto, para que o preconceito seja combatido na sala de aula, é preciso que o professor reconheça essa realidade presente na escola. Durante a realização de revisão bibliográfica deste trabalho notamos que muito foi discutido sobre as diferenças socioeconômicas e a forma como elas influenciavam nas práticas escolares, sendo assim perguntamos para as professoras se o contexto socioeconômicos dos alunos influenciava de alguma forma o aprendizado. 
O contexto socioeconômico influencia na aprendizagem quando associado a baixa cultura (P2). Algumas famílias tem condições de oferecer lazer e cultura ao seu filho (a), outros não. Ou até mesmo outros recursos pedagógicos para complementar o estudo em sala. E a criança desassistida da família acaba sendo prejudicada no aprendizado (isso quando a criança apresenta dificuldades no aprendizado) (P3).

Ao analisarmos as respostas das professoras nos deparamos com uma realidade apresentada neste trabalho, de que aquele (professor) que deveria ser o mediador do trabalho sobre a diversidade, acaba sendo o propagador do preconceito. Encontramos na fala das professoras respostas, tais como: "músicas de qualidade", "baixa cultura"; o que nos revela que há uma supervalorização da cultura erudita/elitista. Perrenoud (2001, p.54) afirma que "para os membros mais conservadores da elite, sua cultura é A cultura. Parece que não existe outra cultura digna desse nome: "ou se tem ou não se tem!" é simples. Os outros se caracterizam por uma ausência de cultura". Pode-se dizer ainda que é sancionado pelo educador o que é bom e aceitável de acordo com sua visão de mundo.

Ainda na expectativa de encontrar alguma prática favorável ao desenvolvimento da criança, em sua convivência com a diversidade cultural, foi perguntado as professoras se o conviver com o diferente de nós na escola é importante para a formação das crianças. Assim responderam:

Conviver com a diversidade (pessoas com as mais diferentes características físicas e psicológicas, valores culturais e história de vida) é uma ótima oportunidade para a promoção de valores como respeito, tolerância, valorizar as diferenças e combater e eliminar qualquer forma de preconceito e discriminação (P1).

Nos da experiência para o autoconhecimento e que auxilia no cuidado da criança (P4).

Embora todas as professoras tenham respondido que conviver com a diversidade é importante percebemos que há muita confusão ao entender como isso contribui para o desenvolvimento da criança, vale destacar que apenas a P4 fez referência ao fato de que conviver com o outro diferente, traz autoconhecimento.

De acordo com Gusmão (2000) é na troca de experiências, no convívio com o diferente à mim que eu me reconheço como pessoa, que trabalho a formação da minha própria identidade; é observando o outro e o que o torna diferente de mim, que compreendo aquilo que de fato sou.

Por fim, para que a antropologia cultural seja colocada em prática na sala de aula, é necessário que primeiramente o professor conheça a realidade de seus alunos, tendo como base essas individualidades presentes no ambiente ele saiba nortear seus ensinamentos, na busca de uma prática capaz de transformar a realidade dos educandos. Assim, foi perguntado as educadoras se o conhecer a realidade de cada aluno é importante para o trabalho pedagógico.

As respostas obtidas nos leva a uma determinada constatação de uma realidade escolar, que não compreende a necessidade de conhecer seu aluno para o desenvolvimento das atividades pedagógicas. Todas as professoras disseram ser importante conhecer a individualidade de cada aluno, mas nenhuma delas destacou que para o planejamento da aula, isso é necessário; tão menos destacaram a importância disso para o trabalho individual com cada aluno, trabalhando as dificuldades de aprendizagem de cada um.

Ao concluir essa análise foi possível analisar que a prática pedagógica deve ser repensada, a fim de que a educação cumpra seu papel social, de trazer igualdade de direitos a todas as pessoas, independentemente de sua cultura, condição socioeconômica e todas outras diversidades.

\section{CONSIDERAÇÕES FINAIS}

O presente trabalho procurou analisar as diversas possibilidades para uma educação libertadora, 
que combata os preconceitos sociais, culturais, que promova a igualdade em direitos e a equidade social. Para tanto discutimos a importância dos conceitos da antropologia cultural, na intensão de uni-los a prática pedagógica da educação infantil, que é primeiro contato escolar da criança, para que desde o início de sua aprendizagem e socialização, ela os desenvolva.

A partir do estudo realizado, pode-se dizer que a realidade escolar, mesmo que não intencionalmente, tem se apropriado dos padrões sociais de cultura, e tentado padronizar todas as crianças a esses modelos, discriminando aquelas que não se enquadram a eles. A pesquisa de campo nos levou a essa mesma conclusão, no ambiente escolar espera-se que todos os alunos se expressem por meio da cultura predominante do local, desvalorizando os gostos e práticas das crianças com baixo nível socioeconômico.

Infelizmente, foi possível observar que a realidade hoje das escolas está distante, aquém do que realmente pensamos ser uma escola inclusiva e plural, e a favor de uma educação que possibilite a todos os alunos as mesmas oportunidades de aprendizagem.

Podemos observar que tanto a escola quanto os professores precisam repensar sua prática, trabalhar a valorização da pessoa, dos diversos gostos, valores, culturas, presente no ambiente escolar, e assim mediar essa conduta com os seus alunos.

Por meio deste trabalho foi possível analisar a importância da antropologia cultural como instrumento eficaz para o processo ensino-aprendizagem, uma vez que seus conceitos são essenciais para a realização do trabalho de olhar para as diferenças sem pré-conceitos, entendendo a realidade do outro e compreendendo por que ele vive e age de tal forma, atitude fundamental para que a prática pedagógica favoreça e oportunize à todos os alunos uma aprendizagem significativa.

Concluímos este estudo afirmando que, assim como esperado inicialmente, para uma prática pedagógica que beneficie o aluno, independentemente de suas individualidades, que a antropologia cultural deve ser o alicerce para a realização de todo trabalho pedagógico.

\section{REFERÊNCIAS}

AQUINO, J. G. Diferenças e Preconceitos na escola: alternativas teóricas e práticas. Educação, cultura e desenvolvimento: o que pensam os professores sobre as diferenças individuais. São Paulo: Summus, 1998.

ARIES, P. História social da criança e da família. Trad, Dora Flasksman. $2^{\mathrm{a}}$ Ed. Rio de Janeiro: Editora Guanabara, 1981.

BRASIL. Constituição da República Federativa do Brasil. Constituição de 1988. Brasília, DF: Senado Federal, 1988a. Disponível em: <http://www2.camara.leg.br/legin/fed/consti/1988/constituicao-1988-5outubro-1988-322142-publicacaooriginal-1-pl.html>. Acesso em: 20/10/2018.

BRASIL. Ministério da Educação e Cultura. Lei no 9.394, de 20 de dezembro de 1996. Brasília, DF: MEC, 1996. Disponível em: <http://www2.camara.leg.br/legin/fed/lei/1996/lei-9394-20-dezembro-1996362578-publicacaooriginal-1-pl.html>. Acesso em: 19/10/2018.

BRASIL. Ministério da Educação e do Desporto. Política nacional de educação infantil: pelo direito das crianças de zero a seis anos à Educação. Brasília, DF, MEC/SEB, 2006. Disponível em: $<$ http://portal.mec.gov.br/seb/arquivos/pdf/pol_inf_eduinf.pdf > . Acesso em: 20/10/2018.

BRASIL. Ministério da Educação e do Desporto. Referencial curricular nacional para a educação infantil. Brasília, DF: MEC/SEF, 1998b.

BRASIL. Ministério da Educação e do Desporto. Referencial curricular nacional para a educação infantil. Brasília, DF: MEC/SEF, 1998 b. 
BRASIL. Lei no 8.069, de 13 de julho de 1990. Brasília, DF, 1990. Disponível em:

<http://www.planalto.gov.br/ccivil_03/leis/L8069.htm>. Acesso em: 20/10/2018.

COHN, C. Antropologia da criança. Rio de Janeiro: Zahar, 2005.

CORTESÃO, L.; STOER, S. "Levantando a Pedra": da pedagogia Inter/Multicultural às políticas educacionais numa época de transnacionalização. Porto: Afrontamento, 1999.

FELIPE, J.; ALBUQUERQUE, S.S. de; CORSO, L. V. Para pensar a Educação Infantil: Políticas, Narrativas e Cotidiano. Porto Alegre: Evangraf, UFRGS, 2016.

FERNANDES, R.; KUHLMANN JR., M. Sobre a história da infância. In: FARIA FILHO, L.M.(org). A infância e sua educação - materiais, práticas e representações. Belo Horizonte: Autêntica, 2004.

FREIRE, P. Educação como prática da liberdade. Rio de Janeiro: Paz e Terra, 1983.

GUSMÃO, N.M. M.de. Desafios da Diversidade da Escola. In: Revista Mediações. Universidade Estadual de Londrina. v.5, n.2, jul./dez.2000. p. 9-28. Disponível em: http://www.uel.br/revistas/uel/index.php/mediacoes/article/download/9158/7749>. Acesso em: $24 / 10 / 2018$.

GUSMÃO, N.M. M.de. Olhar viajante: antropologia, criança e aprendizagem. In: Rev. Pro-Posições, Campinas, v. 23, n. 2 (68), maio/ago 2012. p. 161-178. Disponível em:

<http://www.scielo.br/pdf/pp/v23n2/a11v23n2.pdf >. Acesso em: 17/10/2018.

KUHLMANN JR., M. Histórias da educação infantil. In: Revista Brasileira de Educação, mai/Jun/ Jul/ Ago, no 14, 2000. p. 5-19. Disponível em: 〈http://www.scielo.br/pdf/rbedu/n14/n14a02 >. Acesso em: $17 / 10 / 2018$.

KULLER, J.da A. B. Infância, discutindo o termo pelo viés da História. In: VIII Seminário Nacional de Estudos e Pesquisas. História, Sociedade e Educação no Brasil. História, Educação e Transformação: tendências e perspectivas. Universidade Estadual de Campinas. 2009. p. 1-22. Disponível em: $<$ http://www.histedbr.fe.unicamp.br/acer histedbr/seminario/seminario8/files/H43ASEPS.pdf.> Acesso em 27/10/2018.

MARCONI, M. de A.; PRESOTO, Z.M. N. Antropologia - Uma Introdução. São Paulo: Atlas, 2010.

MORAIS, R. Estudos de Filosofia da Cultura. Belo Horizonte: Edições Loyola, 1992.

NETO, M.D. Rousseau: Um olhar sobre a infância e a educação. São Carlos, 2001. Disponível em: < http://www.unicamp.br/ jmarques/cursos/2001 rousseau/mdn.htm>. Acesso em: 05/12/2018.

PERRENOUD, P. A Pedagogia na Escola das Diferenças - Fragmentos de uma sociologia do fracasso.

Trad. Claudia Schilling. Porto Alegre; Artmed Editora, 2001.

PIAGET, J. O juízo moral na criança. São Paulo: Summus, 1994.

ROUSSEAU, J.-J. Emílio ou Da Educação. São Paulo: Martins Fontes, 2004.

SILVA, T. T. Territórios contestados. Petrópolis: Vozes, 1995.

TOMAZI, N.D. Sociologia da Educação. São Paulo: Atual Editora, 1997.

ULlmanN, R.A. Antropologia Cultural. Porto Alegre: Escola Superior de Teologia São Lourenço de Brindes, 1983. 